Nuntius Antiquus, Belo Horizonte, v. 11, n. 1, p. 111-135, 2015

\title{
Ecos da Eneida de Virgílio, e do herói antigo, em $O$ fiel e a pedra de Osman Lins
}

\section{Echoes from Virgil's "Aeneid" and from the ancient hero in Osman Lins's "O fiel e a pedra"}

Matheus Trevizam

Universidade Federal de Minas Gerais (UFMG), Belo Horizonte, Minas Gerais, Brasil. matheustrevizam2000@yahoo.com.br

Resumo: Neste artigo, propomos buscar alguns elementos de coincidência entre a trama do romance $O$ fiel e a pedra, do escritor brasileiro Osman Lins, e a Eneida de Virgílio, que o primeiro decerto considerou como um modelo. Além disso, explicamos na sequência em que medida o protagonista de $O$ fiel e a pedra se aproxima ou afasta do paradigma do herói presente na épica de Virgílio. Dessa maneira, esperamos explicar por que esse romance moderno foi definido como uma espécie de alusão à Eneida, ${ }^{1}$ a despeito das diferenças genéricas, culturais, cronológicas e espaciais aqui envolvidas.

Palavras-chave: Virgílio; Osman Lins; épica; modelo; herói.

${ }^{1}$ MOISÉS, 2011, p. 19: “A alusão constitui expediente formal de remota origem e pode ser encontrada praticamente em todos os tempos. (...) Camões, ao exortar que 'Cessem do sábio Grego e do Troiano/ As navegações grandes que fizeram' (c. I, est. 3), alude a Odisseu e Eneias. Exemplo moderno é-nos dado por Osman Lins, ao transpor para o sertão pernambucano, em O fiel e a pedra (1961), a Eneida, de Virgílio". 
Abstract: In this paper we propose to search for some coincidental elements between the plot of $O$ fiel e a pedra, novel written by the Brazilian writer Osman Lins, and the plot of Virgil's Aeneid, which the first author has considered as a model. Furthermore, in the course of our explanation, we try to explain to what extent the protagonist of $O$ fiel $e$ a pedra reflects the heroic paradigm found in Virgil's epic poem. Thus, we hope to explain why this novel has been defined as a kind of allusion to the Aeneid, despite of the generic, cultural, chronological and spatial differences here concerned.

Keywords: Virgil; Osman Lins; epic poetry; model; hero.

Recebido em 30 de março de 2015.

Aprovado em 25 de junho de 2015.

\section{Introdução e proposição de paralelos aproximados entre elementos da trama da Eneida virgiliana e de O fiel e a pedra}

No romance $O$ fiel e a pedra, ${ }^{2}$ de Osman Lins, surgem várias reminiscências que nos permitem buscar analogias entre ele e a épica clássica, em especial a Eneida de Virgílio. Nosso objetivo, neste artigo, será apontar os principais elementos da intriga do romance que mantêm pontos de contato com a Eneida, bem como comentar aspectos da caracterização do protagonista, Bernardo, à luz de comparações com a personagem heroica de Eneias.

De início, não será vão lembrar alguns traços constitutivos da tessitura romanesca de $O$ fiel e a pedra: o livro focaliza-se na história de Bernardo Vieira Cedro, personagem de um pai de família na iminência de completar 40 anos. A trama se passa, espacialmente, na zona rural ou semiurbanizada das imediações de Vitória do Santo Antão, povoado que se situa no estado de Pernambuco, em plena zona semiárida brasileira. Temporalmente, o entorno cronológico essencial cobre algum momento da década de 30 do século XX, mas com remissões a um passado mais

\footnotetext{
${ }^{2}$ O ano original de publicação do livro foi 1961 [MOISÉS, 2007 (1974), p. 381: “Com efeito, a década de 60 , nada pobre em romances de superior qualidade, decerto ficará assinalada, dentre outros, por O fiel e a pedra".].
} 
remoto, pois, no capítulo segundo, emergem lembranças da infância e juventude de Bernardo como um dos filhos do casal formado pelo "Velho Cedro" e por Lucinda (LINS, 2007, p. 20).

Bernardo nascera, como o irmão - Caetaninho -, em meio a uma existência de certa fartura material, propiciada pelo caráter pródigo do pai (LINS, 2007, p. 20). Depois da morte desse, Caetaninho se apossa de parte dos bens familiares e segue para a construção independente da própria vida (LINS, 2007, p. 22). Frequentavam o sítio da família Cedro, naqueles tempos, os irmãos Álvaro e Teresa, a futura esposa de Bernardo, os quais, por sua vez, eram filhos de Suzana. Álvaro, talvez levado por seu caráter impressionável, veio a apaixonar-se e casar-se por impulso com Cissone, moça "mais velha do que ele, sem família e sem bens, ociosa a seu modo, cheia de manias infantis, que ignorava onde assistiam os pais e nem mesmo sabia se ainda estavam vivos" (LINS, 2007, p. 28 - tratava-se, talvez, de uma filha bastarda do "Velho Cedro"). Dessa união, nasceria Ascânio, único sobrinho de Bernardo e Teresa, deixado órfão, pela morte da mãe, com a idade de três semanas; pela morte do pai, um pouco mais tarde (LINS, 2007, p. 28).

O começo efetivo da história nos mostra o casal Bernardo e Teresa às voltas com as dores da perda de um filho pequeno, chamado José, e da grande pobreza material em que se encontravam, diante dos olhos recriminadores da velha Suzana, a qual jamais desejara o matrimônio de nenhum de seus filhos (LINS, 2007, p. 29). Importa explicar que a pobreza a que aludimos tivera, já, raízes no caráter anormalmente obstinado e ético de Bernardo, pois esse decidira-se por deixar um seguro emprego de funcionário do Posto Fiscal, em Vitória do Santo Antão, para não compactuar com as muitas desonestidades que via em seus colegas e superiores:

- Desafiar um homem na hora em que ele sobe, senhor! O Posto Fiscal não é propriedade de Agripa Coutinho. Não é propriedade do prefeito. Não me responda agora, deixe-me falar. Você fez como poucos, entende? Você, a bem dizer, não era nada; e mandou para o diabo segurança e acomodação. (LINS, 2007, p. 45)

O "dono" da fala cujo trecho transcrevemos é Miguel Benício, homem mais experiente, rico comerciante e dono de terras naquela localidade pernambucana. Bastante comovido com a má situação do 
honesto Bernardo, ele se decide por ajudá-lo a, de novo, firmar-se na vida em companhia da esposa. O meio encontrado para isso, a saber, foi encarregar Bernardo de assumir a tarefa de vendeiro no Surrão, antigo engenho de fogo-morto que possuía a alguma distância da cidade. Ali, inclusive, o herói poderia criar seus animais, eventualmente plantar sua roça e, aos poucos, reconquistar o equilíbrio perdido um dia.

Depois de o casal ter aceitado a oferta de Miguel Benício, trasladam-se para o barracão da propriedade rural citada, lugar em tudo marcado por grande rudeza e despojamento, mesmo em seus habitantes prévios, como o vigia Xenofonte, Cizilão e sua companheira - Maria Genuína -, Precipício e Tiago (LINS, 2007, p. 59). Para o Surrão também se muda Antônio Chá, antigo companheiro de viagens de Bernardo da época que ele se dedicava a isso que era uma de suas maiores alegrias; deve-se acrescentar que essa figura de amigo seria de grande valia para o apoio e a segurança do casal nos ermos daquele engenho abandonado...

As dificuldades de Bernardo começam quando Miguel Benício morre em circunstâncias misteriosas, ${ }^{3}$ depois de passar falsamente seus muitos bens ao nome de Nestor Benício, seu irmão, para livrá-los no divórcio da posse de Creusa, a esposa adúltera do romance. Então, vindo a aumentar aos poucos os conflitos e desconfianças entre o herói e aquele que passaria a ser seu grande antagonista em O fiel e a pedra, ${ }^{4}$ ocorre no desfecho da história o enfrentamento de vida e morte entre Bernardo e Nestor, o qual resulta na salvação do primeiro e na morte do segundo.

Pela breve descrição que fizemos de O fiel e a pedra, pode-se notar que as semelhanças, sobretudo, com a trama da Eneida, de Virgílio, não são tão óbvias neste caso de cotejo: a título de uma sumária recapitulação,

\footnotetext{
${ }^{3}$ LINS, 2007, p. 120: "Bernardo agora tinha a impressão - obscura e forte - de ser como que uma sobrevivência dele. Único a pressentir a verdade, que adivinhara desde o dia em que vira Nestor ante o irmão e à qual todos pareciam cegos. Pressentia a verdade $\mathrm{e}$ ninguém, senão ele, podia proclamá-la. Olhou para Nestor Benício, duramente: - 'Isso foi crime"”.

${ }^{4} \mathrm{O}$ desonesto Nestor, depois de "apossar-se" da maior parte das terras e negócios de Miguel com a morte dele, objetivava também tomar para si todas as muitas cabeças de gado abrigadas no Surrão; tendo-o impedido Bernardo por saber que não lhe pertenciam, instaura-se em declarado o embate, inclusive ético, entre os dois (LINS, 2007, p. 129-130). Com o passar do tempo, ainda, Nestor passa a pressionar Bernardo com a cobrança exorbitante de aluguéis indevidos por residir no barracão do engenho, algo que seu irmão jamais fizera em vida (LINS, 2007, p. 183-184).
} 
o assunto desse poema antigo eram os eventos atinentes à fuga de Eneias de Troia, depois da destruição da cidade pelos gregos, com alguns companheiros, a fim de fundar as bases de Roma na Itália. De acordo com uma conhecida proposição da crítica (VASCONCELLOS, 2014, p. 84-85), divide-se aproximadamente a Eneida em duas partes, ${ }^{5}$ uma Odisseia e uma Ilíada, correspondendo a primeira ao périplo aventuresco do herói com sua frota até chegar à Itália (cantos I a VI); a segunda, aos sangrentos combates de Eneias contra os rútulos e latinos de Turno, seu rival pela obtenção da mão da princesa Lavínia e o trono (cantos VII a XII). O próprio Osman Lins, no entanto, "semeia" ao longo do romance vários indícios de que deseja propor algum diálogo intertextual entre a epopeia romana e esta sua obra, surgida em pleno período moderno da Literatura brasileira.

Primeiramente, lembramos os dizeres da epígrafe de $O$ fiel e a pedra, os quais incluem a seguinte quadra de origem popular: "Agora conto a história/ de um macho de coragem,/ valente sem pabulagem/ e natural da Vitória". Ora, trata-se de clara remissão à prática épica da propositio do assunto guerreiro, como ocorre, por exemplo, na Eneida virgiliana:

\footnotetext{
${ }^{5}$ Tal divisão remonta, na verdade, pelo menos a Macróbio (Sat. V, 2, 6) e ao comentador do séc. IV d.C., Mário Sérvio Honorato (ad Aen. VII, 1), tendo recebido acolhida, por vezes, não tão pacífica entre todos os latinistas modernos. Assim, Francis Cairns (1989, p. 178) posiciona-se pela prevalência da Odisseia como o modelo básico de Virgílio ao longo de toda a Eneida, e aponta a existência de elementos iliádicos mesmo na parte "odisseica" da epopeia, o que limitaria a bipolarização absoluta do poema latino em seu contato intertextual com Homero; além disso, Homero sequer constitui o único modelo grego incorporado à tessitura da Eneida, pois inclusive se atesta, em passagens dessa obra, a nítida influência de Apolônio de Rodes (CAIRNS, 1989, p. 179, apud ASSUNÇÃO, 2012, p. 71-72). Sem o rechaço absoluto a todas as colocações de Cairns a esse respeito e tendo em vista, sobretudo, o emprego minimamente funcional da antiga tese sobre a bipartição da Eneida, remetemo-nos, porém, à obra de Vasconcellos (2001), na qual o crítico a defende com argumentos que consideramos de valor. Entre esses, poder-se-iam citar a disjunção entre elementos odisseicos e iliádicos, já, desde a propositio da Eneida (VASCONCELLOS, 2001, p. 127-128) e o fato de que, ao contrário do encontrado na trama da Odisseia, o verdadeiro herói virgiliano corresponde não a uma figura particularizada, mas a uma espécie de "encarnação" da coletividade romana (VASCONCELLOS, 2001, p. 117-123 e p. 125-128).
} 
Arma uirumque cano, Troiae qui primus ab oris Italiam, Fato profugus, Lauiniaque uenit litora, multum ille et terris iactatus et alto ui superum saeuae memorem Iunonis ob iram, multa quoque et bello passus, dum conderet urbem 5 inferretque deos Latio, genus unde Latinum Albanique patres, atque altae moenia Romae. ${ }^{6}$

Também em uma questão como a da onomástica de algumas personagens permanecem os elos, ao menos parciais, com o imaginário virgiliano da Eneida: segundo dissemos, o sobrinho de Bernardo e Teresa, em O fiel e a pedra, chama-se Ascânio, nome que se alterna com "Iulo" naquela epopeia latina para designar o filho de Eneias e de Creúsa. Por sua vez, a esposa adúltera de Miguel Benício, contra a qual ele arma o ardil de passar falsamente os seus bens ao nome de Nestor Benício ao pressentir a iminência da própria morte, a fim de salvaguardar o patrimônio dos filhos ainda menores, recebe na trama romanesca moderna o nome de "Creusa". Como se vê, trata-se de aproximações parciais, pois Osman Lins, ao dialogar com o legado de Virgílio, não força artificialmente as analogias (FRITOLI, 2005, p. 133): assim, muda-se o tipo do parentesco entre Ascânio e o protagonista quando pensamos em Virgílio e Osman Lins em conjunto e a personagem da esposa fiel e dedicada da Eneida, primeira consorte de Eneias no poema latino, cede lugar à volúvel Creusa da obra moderna.

Outro pormenor das narrativas de uma e de outra obra postas em paralelo também nos permite aventar a hipótese de que Osman Lins esteja, mais uma vez, convidando o leitor à recordação intertextual de algo outrora mencionado por Virgílio. Ora, os leitores desse poeta antigo estão lembrados de que alguns pressentimentos pareciam prever o belicoso banho de sangue em que se transformou a estada de Eneias e seus companheiros troianos na Itália. Mas, logo ao apresentar-se como

${ }^{6}$ VIRGÍLIO, Eneida I, 1-7: “As armas canto e o varão que, fugindo das plagas de Troia/ por injunções do Destino, instalou-se na Itália primeiro/ e de Lavínio nas praias. A impulso dos deuses por muito/ tempo nos mares e em terras vagou sob as iras de Juno,/ guerras sem fim sustentou para as bases lançar da cidade/ e ao Lácio os deuses trazer - o começo da gente latina,/ dos pais albanos primevos e os muros de Roma altanados". (trad. Carlos Alberto Nunes) 
forasteiro ao rei Latino, pai de Lavínia, com quem deveria casar-se, Eneias é bem recebido por aquele que reconhecia nele o genro a si destinado pelo fatum, em detrimento do itálico Turno (Eneida VII, 255-258). Apenas pelas intrigas de Juno, eterna inimiga dos romanos, a qual insufla o ódio nos corações desse rival e da rainha Amata, mãe de Lavínia, começam a fermentar as condições indispensáveis para a guerra, em uma sequência irreversível de afrontas e tentativas de reparo pela vingança.

Assim, um dos ardis de que se valeu a deusa foi fazer com que a Fúria Alecto levasse "os cães de Iulo a caçar um cervo, animal de estimação de Sílvia, filha do responsável pelos rebanhos do reino (de Latino)" (VASCONCELLOS, 2014, p. 64). A triste morte do cervo, na verdade, acabou por representar, na Eneida, o estopim para a deflagração da guerra entre os troianos e os locais (VIRGÍLIO, Eneida VII, 481 et seq.).Ora, em O fiel e a pedra, tem-se na misteriosa morte de um bezerro de estimação de Teresa, a esposa de Bernardo, mais um agravante para a piora das relações entre o herói e os suspeitos habitantes do engenho, que não passavam, no final das contas, de homens a serviço de seu inimigo, Nestor Benício:

Teresa veio, com a mão esquerda apertou o braço esquerdo do esposo e durante alguns segundos ninguém se moveu. "- Veja a desgraça que fizeram, minha velha". O ubre cheio, alheia ao tumulto do garrote e da novilha, a vaca lambia o filho morto, certamente julgava-o adormecido. "Ele não vem mais soprar na minha mão"-pensou Teresa. "Por que fazem isso, por que essa perseguição?" (LINS, 2007, p. 245)

Ainda de acordo com o procedimento de Osman Lins de não portar-se, em tudo, coincidentemente com Virgílio, nota-se que, no contexto do romance moderno, os ofendidos com a morte de um animal de estimação - que é, enfim, não um cervo das matas, mas um simples bezerro nascido em um curral de engenho! - correspondem aos "estranhos" Bernardo e Teresa, não aos primeiros habitantes ou ao dono do Surrão. Outro importante elemento de ligação entre os procedimentos encontráveis na trama de $O$ fiel e a pedra e aqueles da Eneida diz respeito à aparição de entes "sobrenaturais", sejam eles deuses ou fantasmas, em meio ao mundo humano. 
Um estranho episódio vivenciado por Ascânio no romance moderno, assim, conta-nos como, tendo o menino pressentido a presença noturna de alguém no quarto ao lado do seu, que se separava dele por uma divisória de vidro, veio a descobrir tratar-se de ninguém menos que sua mãe morta, a bastarda Cissone. ${ }^{7}$ Ora, no canto II da Eneida, como se lembram os leitores de Virgílio, a mãe do "original" Ascânio, Creúsa, também aparece fantasmagoricamente a Eneias quando ele retorna a Troia já incendiada pelos gregos, depois de ter retirado dali o filho, o pai - Anquises - e as imagens dos deuses pátrios e notar que desconhecia o paradeiro da esposa extraviada. A fala tranquilizadora de Creúsa, nesse momento, é a de uma morta conformada com seu destino e que sabe que o marido deve deixar seu passado troiano para trás, rumo ao Ocidente e até às bodas com uma estrangeira, a princesa itálica Lavínia (Eneida II, 771-789).

Outra aparição de ente "sobrenatural" de O fiel e a pedra cujos sentidos evocam fortemente algo já constante da Eneida diz respeito ao que temos no capítulo 42 e menciona Vênus, desde o título. ${ }^{8}$ No contexto original, tratava-se da parte em que essa deusa, mãe de Eneias, descia ao mundo dos homens para entregar-lhe seu magnífico escudo, obra de Vulcano:

At Venus aetherios inter dea candida nimbos
dona ferens aderat; natumque in ualle reducta
ut procul e gelido secretum fumine uidit,
talibus affata est dictis seque obtulit ultro:
"En perfecta mei promissa coniugis arte
munera, ne mox aut Laurentes, nate, superbos
aut acrem dubites in proelia poscere Turnum".

${ }^{7}$ LINS, 2007, p. 31: "Voltara-se: além do véu da cama e mal iluminada pela luz escassa, uma figura estava de pé. Num gesto que lembrava o de Teresa, abrira o véu - e Ascânio contemplara-a, extasiado. Que brilho tinham aqueles olhos e como, sendo tão pouca a luz, via-a tão bem. '- Quem é a senhora?' A mulher respondera que era sua mãe, fechara o véu, abrira a porta que dava para a sala de visitas e desaparecera fechando-a atrás de si”.

${ }^{8}$ LINS, 2007, p. 283: "Nuvem protetora: 'E Vênus, a branca deusa, entre celestes nuvens, era presente e trazia o dom"”.

${ }^{9}$ VIRGÍlIO, Eneida VIII, 608-614: “A deusa Vênus, no entanto, esplendente se achava nas nuvens/ mais lampejantes de perto, com os dons prometidos ao filho./ Tão logo 
No romance brasileiro, quem aparece ao herói, Bernardo, é sua mãe morta, Lucinda, em certa noite chuvosa em que ele, talvez, adormecera. Apesar dos tons de indefinição do teor dessa experiência para o leitor - Bernardo tivera algum contato com Lucinda em sonhos ou no plano mais "concreto" dos seres em vigília? -, é um fato que as sensações daí advindas, então, figuraram-se-lhe muito reais. ${ }^{10}$ Ainda, tal "visita" tivera o propósito, assim como aquela de Vênus a Eneias, nos versos transcritos há pouco, de aconselhar e fortalecer Bernardo diante de seu embate cada vez mais acirrado com o desonesto e insidioso Nestor Benício (não contra o rútulo Turno, evidentemente):

Não fizesse aquilo, não matasse Nestor, não manchasse de sangue as suas mãos. Confiasse e não temesse, ela haveria de guardá-lo. E também não se fosse, não fugisse. Ficasse. Revestido de fé, entregue à sua proteção, ficasse. Ela o amparava, ela o envolvia, ela o resguardava contra os cães. (LINS, 2007, p. 286)

Quanto ao aspecto do fluxo geral dos acontecimentos em $O$ fiel e a pedra, parece-nos destacar-se, quando pensamos em suas semelhanças com o tema e a estrutura da Eneida virgiliana, o ponto dos "combates" de Bernardo contra a astúcia e a violência de Nestor, na fase posterior à morte de Miguel e quando o Surrão já se encontrava, ao menos burocraticamente, sob a posse daquele antagonista. Trata-se, assim, de uma espécie de "duelo" não apenas pelo domínio (temporário) das terras em jogo, ${ }^{11}$ mas também pela prevalência ética de valores completamente

o viu num dos vales do ameno ribeiro, na frente/ dele se pôs e sem mores delongas destarte falou-lhe: 'Eis o presente que te prometi, prenda excelsa do gênio/ do meu marido! De agora em diante, meu filho, não temas/ aos laurentinos opor-te ou a Turno enfrentar nos combates"'. (trad. Carlos Alberto Nunes)

${ }^{10}$ LINS, 2007, p. 285: "Havia alguém na sala, alguém o visitava, uma visita de misericórdia, com as mãos tão fortemente cruzadas que essa força parecia expandir-se, comunicar-se às mãos dele. E não sentira aquelas mãos insinuarem-se entre as suas, nem o deslizar da pele, nem a pressão que elas deviam ter feito".

${ }^{11}$ Ao final do capítulo 49 de O fiel e a pedra, Bernardo parte definitivamente do Surrão depois de enfrentar pelas armas Nestor Benício e seus "capangas", como Marvano e Ubaldo. No conflito, Bernardo é ferido a bala pelos aliados de Nestor, mas Antônio Chá reage e mata esse inimigo, retirando depois o patrão para a cidade em lombo de burro e caminhão (LINS, 2007, p. 371). Bernardo, enfim, cura-se e sobrevive... 
distintos. O contraponto desses eventos na própria épica romana a que temos aludido são, sem sombra de dúvida, os enfrentamentos militares entre, por um lado, Eneias com seus aliados - os troianos, os árcades de Evandro etc. - e, por outro, Turno com os rútulos e latinos, como esses ocorrem a partir do canto VII da Eneida. Exceção feita a algumas vagas alusões às "viagens" de Bernardo no começo do romance brasileiro (LINS, 2007, p. 35), nada há de muito evocativo da parte "odisseica" do poema antigo na obra de Osman Lins, ${ }^{12}$ vindo assim a ocorrer que o elemento "iliádico" da épica, relativo à guerra na Itália mesma, presentifique-se mais como polo de diálogo com Virgílio nesse texto moderno.

\section{Aproximações possíveis, ou não, entre Eneias, personagem heroi- ca em Virgílio, e Bernardo Vieira Cedro, seu "correspondente" no romance moderno de Osman Lins}

Neste ponto, talvez não seja sem valia apontar algumas características geralmente associáveis às personagens heroicas nas Literaturas clássicas. O mitólogo francês Georges Dumézil, com seu conhecido modelo "trifuncional" sobre as sociedades indo-europeias, pode oferecer-nos alguns pressupostos passíveis de instrumentalizar-se para comentários a respeito do assunto na Eneida, e sua posterior comparação com o elemento heroico em $O$ fiel e a pedra. A título de uma sumária recapitulação, lembramos que a primeira "função" que ele reconhece operativamente nessas sociedades corresponde àquela da soberania "mágica e jurídico-religiosa"; a segunda, à da "força física, utilizada principalmente para o combate"; a terceira, enfim, à da "fecundidade, com suas condições e seus efeitos". O mesmo erudito também enfatiza que tal estruturação operativa e de pensamento, "depois de ter dominado a ideologia dos indo-europeus, sobreviveu longamente, a despeito das vicissitudes da pré-história e da história, na maior parte das sociedades de componente indo-europeu forte" (DUMÉZIL, 1986b, p. 675). ${ }^{13}$

\footnotetext{
${ }^{12}$ Não se tem, a título de exemplificação, um episódio de amor tempestuoso em $O$ fiel e a pedra, tal como esse ocorre na Eneida com o entrecho de Eneias e Dido no canto IV do poema. Ainda, o amor conjugal de Bernardo e Teresa, que permanece como algo constante ao longo da trama do romance moderno, nada tem de desestruturador dos propósitos heroicos de Bernardo, na medida em que essa mulher, à sua maneira, até acompanha o marido em suas lutas diárias.

${ }^{13}$ DUMÉZIL, 1986b, p. 675: “ (...) après avoir dominé l’idéologie des Indo-Européens, a survécu longtemps, en dépit des vicissitudes de la préhistoire et de l'histoire, dans la
} 
Em parte distinta de sua vastíssima obra, ainda, Dumézil apresenta-nos dados concernentes à distribuição de certos elementos étnicos da Eneida entre as três "funções" citadas. Desse modo, quando se tomam os troianos/Eneias, os etruscos/Tarchão e os latinos/rei Latino, veem-se, para ele, mostras de algum "saber" de Virgílio no tocante a tais estruturas, ao pensarmos em todas as lendas em vínculos com a origem remota do povo romano de que se serviu o vate para compor seu poema épico. ${ }^{14}$ Se desejamos, propriamente, acompanhar-lhes os raciocínios que propiciaram atribuir a Eneias, sobretudo, a primeira "função", a Tarchão a segunda e a Latino a terceira, é de interesse lembrar que o protagonista da Eneida, na verdade, inicia cronologicamente a própria trajetória como uma espécie de guerreiro: ${ }^{15}$

Arma amens capio; nec sat rationis in armis, sed glomerare manum bello et concurrere in arcem 315 cum sociis ardent animi; furor iraque mentem praecipitant, pulchrumque mori succurrit in armis. ${ }^{16}$

plupart des sociétés à composante indo-européenne forte". (trad. minha)

${ }^{14}$ DUMÉZIL, 1986a, p. 437: "Le fait que Virgile ait pu si bien transposer la structure de la 'naissance de Rome', confirme donc l'impression que nous donnait naguère le début de la première Élégie romaine de Properce: en plein siècle d'Auguste, les hommes cultivés savaient, aussi bien que les annalistes qui avaient mis au point cette naissance 350 ou 250 ans plus tôt, quelle philosophie sociale elle exprimait".

${ }_{15}$ Trata-se, para Virgílio, de uma espécie de retomada dos contornos do mesmo Eneias, tal como surgem na Ilíada de Homero. Nesse poema épico fundador, por sinal, tendo o herói recebido algum destaque por sua bravura em combate, mostra-se-nos ele representado com algum brilho em vários cantos (II, 819 et seq.; V, 166-275; V, 297-317; V, 431-470; V, 512-518; V, 541-572; XII, 98; XIII, 458-505; XIII, 540-544; XV, 332-338; XVI, 608-631; XVII, 333 et seq.; XVII, 491-536; XVII, 752; XVII, 761; XX, 75-352). Mas, já em XX, 306 et seq., refere-se profeticamente a tradição segundo a qual Eneias haveria de sobreviver aos gregos e reinar sobre seu povo: "Já os descendentes de Príamo são pelo Crônida odiados;/ mas há de o mando exercer nos troianos Eneias, o forte,/ e quantos filhos, depois, de seus filhos a luz contemplarem". (trad. Carlos Alberto Nunes)

${ }^{16}$ VIRGÍlLIO, Eneida II, 314-317: "Fora de mim, logo as armas procuro; de nada nos servem./ Um pensamento a nós todos anima: voar para os pontos/ onde a batalha mais forte estrondava. Uma ideia somente/ nos exaltava: era belo morrer em defesa da pátria". (trad. Carlos Alberto Nunes) 
Talibus Othryadae dictis et numine diuum in flammas et in arma feror, quo tristis Erinys, ullo fremitus uocat et sublatus ad aethera clamor. Addunt se socios Ripheus et maximus armis Epytus, oblati per lunam; Hypanisque Dymasque, et lateri agglomerant nostro iunenisque Coroebus, Mygdonides: (... $)^{17}$

Quos ubi confertos audere in proelia uidi, incipio super his: "Iunenes, fortissima frustra pectora, si uobis audentem extrema cupido certa sequi, quae sit rebus Fortuna uidetis: excessere omnes adytis arisque relictis di quibus imperium hoc steterat; succurritis urbi incensae; moriamur, et in media arma ruamus. Vna salus uictis nullam sperare salutem". ${ }^{18}$

Aos poucos, porém, consolidando-se mais e mais a queda definitiva de Troia diante da fúria grega (e divina!) e da morte de vários dos companheiros de Eneias, o herói, avisado pela própria mãe, a deusa Vênus, recua em seus propósitos de início e começa a pôr-se em maior acordo com os desígnios do fatum (Eneida II, 619-620). Ora, esse corresponde em tal poema épico, como há pouco dissemos a partir das pesquisas de Dumézil, ao gradativo desempenho de papéis em nexo com os atributos da realeza e da condução religiosa dos remanescentes do povo de Troia (DUMÉZIL, 1986a, p. 421 et seq.). Por sinal, antes mesmo de pegar em armas na noite derradeira de Ílio, Eneias recebera em sonhos, dos lábios do espectro de Heitor, dizeres condizentes com a fatídica deposição de papéis "sacerdotais" e de liderança sobre si:

\footnotetext{
${ }^{17}$ VIRGÍLIO, Eneida II, 336-342: “A essas palavras do Otríada e aos próprios ditames dos deuses/ corro ao encontro das armas, do fogo, das tristes Erínias,/ ao grande estrondo dos ferros, clamor que até aos astros ecoa./ A mim se agrega Rifeu juntamente com Épito, o grande/ e venerável guerreiro, do luar amparados, mais Hípanis,/ o alto Dimante, seguido do jovem Corebo Migdônida, / (...)". (trad. Carlos Alberto Nunes) ${ }^{18}$ VIRGÍlLIO, Eneida II, 347-354: "Vendo-os dispostos a entrar na peleja, tomados de brio,/ disse-lhes: 'Jovens de inútil esforço e ousadia! No caso/ de me acolherdes o apelo para uma entrepresa arriscada,/ quase loucura, bem vedes para onde a Fortuna bandeouse:/ todos os deuses, esteios da pátria, os santuários e altares/ já abandonaram. Correis em defesa de ruínas e escombros/ em labaredas. Morramos, então! Avancemos sem medo!/ Para os vencidos só há salvação na esperança perdida"”. (trad. Carlos Alberto Nunes)
} 
"Heu fuge, nate dea, teque his", ait, "eripe flammis.

Hostis habet muros; ruit alto a culmine Troia.

Sat patriae Priamoque datum: si Pergama dextra defendi possent, etiam hac defensa fuissent.

Sacra suosque tibi commendat Troia Penates; hos cape fatorum comites, his moenia quaere magna, pererrato statues quae denique ponto". Sic ait et manibus uittas Vestamque potentem 295 aeternumque adytis effert penetralibus ignem. ${ }^{19}$

Na parte grifada da citação, depois de posicionar-se pela nulidade circunstancial de quaisquer esforços de luta, Heitor fala a Eneias da recomendação dos sacra - "objetos sagrados", mas também "ritos", em possível tradução - e Penates aos seus cuidados, necessitando ele salválos consigo (e os seus) das chamas e da destruição iminentes. Ainda, ele deverá resguardá-los em uma nova cidade que há de fundar alhures, ${ }^{20}$ como se nota pela referência às muralhas a serem um dia "estabelecidas" (statues, v. 295) pelo herói, depois de muito vagar em rota marítima. Ora, Penates justamente são entes sagrados que se associaram, entre os latinos, à garantia de abastecimento material - com comida e bebida, a saber - para as casas ou cidades; eram inclusive cultuados e mantidos, sob a forma de pequenas estatuetas, no altar doméstico, o lararium, cujo chefe de culto correspondia ao pater familias (HACQUARD; DAUTRY; MAISANI, 1952, p. 23). Por sua vez, Vesta era uma das mais importantes divindades dos romanos, vinculando-se à chama mantida permanentemente acesa no interior de seu templo urbano o sentido da própria sobrevivência da Cidade (ROBERT, 1999, p. 168). Isso significa

${ }^{19}$ VIRGÍLIO, Eneida II, 289-297: “"Foge daqui, filho de uma deidade; do incêndio te livra./ Dentro dos muros campeia o inimigo; hoje Troia extinguiu-se./ Muito já demos a Príamo e à pátria. Se a Pérgamo a destra/ de algo valesse, estas mãos se imporiam na sua defesa./ Troia te entrega os seus deuses e os sacros objetos do culto./ Leva contigo esses sócios; procura morada para eles,/grande cidade, depois de cortares o mar tormentoso'. Disse, e entregou-me as sagradas insignias e Vesta potente, / e o fogo eterno que ardia no lar, no santuário profundo". (trad. Carlos Alberto Nunes) ${ }^{20}$ A cidade que há de estabelecer Eneias no Lácio não é, evidentemente, Alba-Longa, cujo fundador corresponderia, um dia, a seu descendente Iulo (Eneida VIII, 26 et seq.), nem muito menos Roma, "obra" do lendário Rômulo, suposto filho da vestal Reia Sílvia e de Marte. Trata-se, antes, do sítio de Lavínio (Eneida I, 2), que teria de esperar mais trinta anos, depois de nascer, até o surgimento de Alba-Longa por iniciativa de Iulo. 
que Heitor, nesse momento de prenúncio do destino final de Eneias, transmite-lhe algumas das bases do culto pátrio dos troianos, tendo elas, antes de mais nada, de ser transplantadas e mantidas vivas pelo herói nas "novas" paragens do Ocidente. ${ }^{21}$

Evidentemente, na dita "segunda parte" da Eneida - cantos VII a XII, sobretudo -, depois de assumir aos poucos a liderança definitiva de seu povo na falta de Anquises, ${ }^{22}$ figura paterna cuja morte nos é relatada no canto III da epopeia, Eneias surge envolvido de forma direta em várias situações de conflito armado, vindo, inclusive, a sacrificar Turno com as próprias mãos no desfecho da obra (Eneida XII, 947952). Relaciona-se a prevalência da "primeira função" para Eneias, no entanto, não só ao "ponto de chegada" de seu destino derradeiro, mas a algo em nexos com a própria caracterização essencial desse herói. ${ }^{23}$ Sucessivamente, os leitores do épico virgiliano têm ressaltado que tal personagem se caracteriza pelo atributo da pietas (DUMÉZIL, 1986a, p. 414-415; COULANGES, 2004, p. 154; VASCONCELLOS, 2014, p. 82-83), devendo-se frisar que seu domínio ultrapassa

${ }^{21}$ A respeito da têmpera particular do caráter de Eneias e de sua "missão", sobretudo no contraste com a inigualável coragem guerreira de um Aquiles e a astúcia de Odisseu, vejam-se, sob um prisma conceitual diferente do de Dumézil, mas decerto não conflitante com esse e ainda acertado, apesar dos anos, as palavras de Fustel de Coulanges (2004, p. 153-154): "A chegada de Eneias, ou antes, o transporte dos deuses de Troia para a Itália, constitui o tema da Eneida. O poeta canta esse homem, atravessando os mares para ir fundar a sua urbe e levar os seus deuses para o Lácio (...). Não se trata aqui do guerreiro ou do herói de um romance. O poeta quer apresentar-nos um sacerdote. Eneias é um chefe do culto, um homem sagrado, o divino fundador cuja missão está em salvar os Penates da cidade".

${ }^{22}$ VASCONCELLOS, 2014, p. 52: "Neste livro [o III], vemos os troianos vagarem sem rumo e incertos de seu fado até se esclarecerem sobre a terra que lhes estava destinada. Anquises parece ser o verdadeiro líder dos exilados, papel que, à sua morte, caberá a Eneias".

${ }^{23}$ DUMÉZIL, 1986a, p. 418-419: "Romulus, Énée ont donc une nature plus riche que Lucumon, que Tarchon, substitué à Evandre: structuralement, ceux-ci appartiennent entièrement à la deuxième fonction; chez ceux-là, la deuxième fonction est comme un prolongement inséparable de la première, un moyen naturel au service de la première. (...) Le caractère quasi sacerdotal d'Énée se manifeste naturellement moins dans les livres consacrés aux combats que dans la première moitié du poème". 
o da religião: ele concerne tanto as relações corretas com os pais, os amigos ou os concidadãos quanto a atitude correta para com os deuses. A piedade funciona como uma justiça distributiva, regendo as obrigações dos homens diante dos deuses. "A piedade é a justiça para com os deuses", escreve Cícero (Da natureza dos deuses 1,116). Essa virtude social é recíproca e os deuses também devem cumprir suas obrigações. ${ }^{24}$

Nesse sentido mais estendido da pietas, tão fortemente associável ao peculiar heroísmo de Eneias, pode-se falar aqui do esboço, por Virgílio, dos contornos de uma personagem não só religiosa, mas ainda ética, na medida em que se compromete com a correta conduta diante de todos aqueles ligados a si pelos laços da reverência, da amizade e do sangue. ${ }^{25}$ O exemplo mais conhecido da piedade desse herói corresponde, talvez, à cena da fuga de Troia em chamas, com o velho Anquises às costas, as imagens dos deuses de Troia nos braços, Iulo ao flanco e Creúsa, que se acaba perdendo, logo atrás (Eneida II, 707-711). Acrescente-se, em breve retomada de algumas posições de Dumézil acima anunciadas, que esse estudioso atribui a um chefe etrusco, Tarchão, a prevalência da segunda "função" - guerreira - por seus próprios contornos constitutivos, bem como por aqueles do povo etrusco, de cujas tendências se faz, muitas vezes, uma espécie de "encarnação" (DUMÉZIL, 1986a, p. 404-405). Assim, como relembra o mitólogo, Eneias recebe como aliada a "Etrúria inteira" (Eneida VIII, 473), a qual, contribuindo com trinta navios

${ }^{24}$ SCHEID, 2010, p. 26: "Le domaine d'application de la piété dépasse celui de la religion: il concerne aussi bien les relations correctes avec les parents, les amis ou les concitoyens que l'attitude correcte à l'égard des dieux. La piété fonctionne comme une justice distributive, régissant les obligations des hommes envers les dieux. 'La piété est la justice à l'égard des dieux', écrit Cicéron (De la nature des dieux 1,116). Cette vertu sociale est réciproque et les dieux aussi doivent remplir leurs obligations". (trad. minha) ${ }^{25} \mathrm{Na}$ introdução a uma recente edição da Eneida de Virgílio, traduzida por Carlos Alberto Nunes, João Angelo Oliva Neto posicionou-se sobre o lado, de fato, fortemente ético da caracterização de Eneias (OLIVA NETO, 2014, p. 28-31). Assim, ele é justo e manifesta compreensão para com seus subalternos, "quando a alguns deles, já exaustos da viagem, concede que permaneçam na Sicília (V, vv. 700-56)"; mesmo no tocante a Dido, que abandonou em desespero em Cartago depois de envolver-se amorosamente com ela, fica claro que não o fez de forma leviana, mas a mando de um inexorável destino, o qual o obrigava a alcançar a Itália (Eneida IV, 361). 
carregados de homens dispostos ao combate, dá boa mostra dos pendores guerreiros de seus filhos. No canto $X$ da epopeia virgiliana, ainda, os etruscos se caracterizam por serem uma "tropa armada" (manus, v. 164), bem como uma "tropa de elite" (lecta manus, v. 294), que tem "seus generais, seu próprio generalíssimo, um rex, mas espera outra coisa, um chefe, um $d u x$ providencial". ${ }^{26}$ Além disso, não se aguarda o $d u x$ em uma cidade, mas em campo aberto, de forma que esse campo, à diferença de outros sítios mencionados na Eneida, não prefigura a fundação de uma nova urbs; trata-se tal lugar de assentamento das tropas da Etrúria de castra - "acampamentos" -, como ressalta várias vezes o poeta (canto VIII, 476, 507 e 604; X, 148), ocupados por uma acies - "linha de batalha" ou uma legio - "legião" -, posta sob tendas (VIII, 604-605); por fim, tal contingente é especializado, constituem-no "sobretudo cavaleiros, alae, a que o combate a pé molesta, mas que, por isso mesmo, completam bem o exército troiano". ${ }^{27}$

Por outro lado, seu comandante, Tarchão, que é chamado apenas uma única vez de rex, porém de uma cidade etrusca indefinida, se caracteriza, na visão de Dumézil, pelo papel de um dedicado oficial, sem jamais questionar ou pôr-se em pé de igualdade com Eneias, a quem obedece não como um par, mas como subordinado, controlando uma tropa apresentada ao modo de um "exército profissional" (DUMÉZIL, 1986a, p. 405). Quando, porém, pensamos na figura do rei Latino, à qual se associa a posse da terra de que Eneias haveria de assenhorear-se pelo casamento político com a princesa Lavínia, ocorre a manifestação de traços concernentes à terceira "função" - a da fecundidade - na medida em que essa personagem de um fraco, mas opulento soberano, constituise, com seu povo, na via de acesso a uma esposa e a campos férteis para o herói (DUMÉZIL, 1986a, p. 388). Os latinos, ainda, caracterizam-se na Eneida por favorecerem a "prosperidade, a riqueza e também, antes dos combates, a paz e o gosto da paz". ${ }^{28}$ Lembramos, aqui, que esse povo apenas entra na guerra contra Eneias e seus aliados depois de haver a incitação demoníaca de Juno, através das Fúrias, à rainha Amata, mãe

${ }^{26}$ DUMÉZIL, 1986a, p. 404: “(...) ses généraux, son généralissime même, lequel est un rex, mais qui attend autre chose, un chef, un dux providentiel". (trad. minha)

${ }^{27}$ DUMÉZIL, 1986a, p. 404: “(...) surtout des cavaliers, alae, que gêne le combat à pied, mais qui, par cela même, complètent bien l'armée troyenne”. (trad. minha)

${ }^{28}$ DUMÉZIL, 1986a, p. 388: “(...) la prospérité, la richesse et aussi, avant les combats, la paix et le goût de la paix” (...). (trad. minha) 
de Lavínia, e a Turno (Eneida VII, 325-326; VII, 461-462), e que, ao saber da efetiva deflagração bélica, o próprio rei Latino se retira para o interior do palácio, deixando, com desgosto, os combatentes entregues à sua sorte:

"Nam mihi parta quies, omnisque in limine portus; funere felici spolior". Nec plura locutus saepsit se tectis rerumque reliquit habenas. ${ }^{29}$

Curiosamente, vê-se em $O$ fiel e a pedra a figura de um herói "forasteiro" ${ }^{30}$ e que, não sendo efetivo líder de povo ou facção alguma, não se envolve de forma concentrada em estritas escaramuças com quaisquer inimigos: os dois únicos momentos do romance vinculados a tons mais corporais de disputa contra opositores correspondem ao que vemos nos capítulos 40 e 49. ${ }^{31}$ No capítulo 40, por sinal, quando Bernardo seguia de Vitória para o Surrão em lombo de burro, ouviu um estampido vindo de uma zona de mata fechada, já nas imediações do engenho: logo percebeu ser um tiro com que, no mínimo, pretendiam intimidá-lo. Ele, na sequência, lembrou-se de Teresa, com "desejo de sobreviver", mas seguiu-se outro tiro e então ficou claro que se tratava, de fato, de covarde tentativa de matá-lo às escuras (LINS, 2007, p. 272-273). Note-se que, nesse episódio, há completa desigualdade no aspecto do ataque físico ao inimigo, pois Bernardo, que seguia desarmado e sequer sem saber exatamente quem tentava atingi-lo, nenhuma reação pôde esboçar a não ser seguindo adiante para salvar-se.

Em uma tese especificamente destinada ao propósito de investigar os elementos das epopeias clássicas tal como esses, de algum modo, foram incorporados também à trama moderna de O fiel e a pedra, Rosa Walda Marquart destacou entre outros, na caracterização heroica de Aquiles, Odisseu, Eneias e Bernardo Vieira Cedro, traços como a valentia, a ira,

${ }^{29}$ VIRGÍLIO, Eneida VII, 598-600: "Enquanto a mim, tenho já como certo um futuro tranquilo;/ do porto à vista já estou. Só me privam de exéquias solenes"./ Disse, e encerrou-se no paço, largando o timão do governo". (trad. Carlos Alberto Nunes)

${ }^{30}$ Sobre tal traço da caracterização de Eneias, cf. DUMÉZIL, 1986a, p. 380; no tocante a Bernardo, basta pensar que o engenho onde se fixa com a esposa e Antônio Chá não era propriedade sua, mas fora-lhe oferecido para a moradia por Miguel Benício.

${ }^{31}$ Sobre a ocorrência do capítulo 49 , que, na verdade, corresponde ao próprio desfecho do embate entre Nestor Benício e Bernardo, cf. nota 11. 
a astúcia (ou inteligência), a prudência e sensatez, o impulso construtor e a "piedade", segundo suas próprias palavras (MARQUART, 2008, p. 7-91). Sem ser preciso que todas essas características estejam presentes em todas as figuras heroicas citadas, ou até com a mesma intensidade (ou clara definição), para Marquart elas se encontrariam, sob a forma de "feixes" variáveis em cada caso, representadas em conjunto, por exemplo, em Eneias e Bernardo.

A mesma estudiosa, justamente, destaca em Aquiles, e até em Odisseu e Bernardo - ${ }^{32}$ não tanto no Eneias virgiliano -, ${ }^{33}$ o traço da valentia (MARQUART, 2008, p. 8-9); sobretudo no próprio Aquiles, a ira, sem descartar-lhe a presença na eventual atuação de Odisseu, Eneias e até Bernardo $^{34}$ (MARQUART, 2008, p. 28); a astúcia, para os conhecedores das literaturas de matrizes clássicas, evidentemente se vê com primazia no caráter de Odisseu, sem o imediato desdouro dos demais heróis ${ }^{35}$ nesse quesito (MARQUART, 2008, p. 34-37); a prudência e sensatez correspondem a um âmbito moral privilegiado entre os antigos, para essa crítica, nas atitudes de Odisseu e Eneias, ${ }^{36}$ mas não tão obviamente em Bernardo, sempre disposto ao desafio a Nestor Benício mesmo quando

${ }^{32}$ Cf. acima, para um exemplo da valentia - moral - de Bernardo, primeira citação transcrita de Lins. (2007, p. 45)

${ }^{33}$ MARQUART, 2008, p. 9: "Eneias, além de piedoso, é também chamado valoroso (uma vez, apenas), fatal, indígite; o que torna visível o quanto a personagem se afasta de seu perfil iliádico. Essa dicotomia se dá, em parte, pelo caráter mais delicado e não tão violento como o troiano da Ilíada e também pela diferença de estilo entre Homero e Virgílio".

${ }^{34}$ LINS, 2007, p. 222: "Sua ira [grifo nosso], a força de seu desafio, concentrara-os no ato temerário, que lhe parecera indispensável e simples, de abrir a porta". Eneias irase, por sua vez, inclusive ao ver Turno rendido a seus pés e pedindo clemência diante da perspectiva da morte, embora portasse as armas do jovem Palante como aviltantes despojos de guerra (Eneida XII, 947-952).

${ }^{35}$ MARQUART, 2008, p. 38: "Inexperiente em outros aspectos, como por exemplo, no amor, Bernardo ainda bem jovem aprende a arte de comercializar e se embrenha pelos vilarejos do sertão pernambucano, oferecendo mercadorias diversas 'figas, voltas, medalhinhas de alumínio, retratos do padre Cícero Romão' (OFP, 24)". Em Eneida IV, 428 , o protagonista busca um "modo mais astuto" de contar a Dido sobre a necessidade de sua partida para a Itália com os troianos, lembra-nos Rosa Marquart (2008, p. 37). ${ }^{36}$ Poderíamos dizer Eneias prudente, por exemplo, ao tratar com cortesia a rainha Dido em sua chegada a Cartago e ao ser reticente no anúncio da partida a essa rainha (Eneida I, 522-557 e IV, 281-298). 
sabia que, decerto, o mais simples e sensato seria apenas afastar-se de um homem tão sem caráter (MARQUART, 2008, p. 46). Tal teimosa obstinação, no entanto, coaduna-se com os propósitos dessa personagem de jamais render-se ao Mal, talvez incorrendo na insensatez contrária de abraçá-lo ou deixá-lo florescer...

O impulso construtor, em certo sentido contrário à fúria destrutiva de Aquiles e Odisseu - por conta da atuação de ambos durante a queda de Ílio,$-{ }^{37}$ decerto se acha bem representado na figura de Eneias, modelo de herói-fundador (DUMÉZIL, 1986a, p. 448-449), mas também em Bernardo:

O esposo de Teresa enxergará possibilidades no Surrão abandonado e tentará modificá-lo através do cultivo da terra e da criação de animais, bem como da ativação de um moinho que adquirira - enfim, o reavivamento do fogo. E tal acontece, gradativamente: a velha fazenda relegada às serpentes e ao mato recupera-se, viceja pelo espírito edificador de seu novo arrendatário. (MARQUART, 2008, p. 49)

Quanto à piedade, que é definida, por Marquart, ao modo de uma "extrema dedicação aos deuses, à pátria e à família" (2008, p. 50), encontrar-se-ia representada não só nos heróis antigos - com evidente destaque para a caracterização de Eneias neste quesito,$-{ }^{38}$ mas ainda, em alguma medida, no próprio Bernardo. A mesma estudiosa, porém, ressalta que o modo peculiarmente assumido pela piedade desse herói de romance moderno são o cuidado e a preocupação com os seus, sem que

${ }^{37}$ MARQUART, 2008, p. 47: “Aquiles e Odisseu são dois grandes destruidores de cidades. O primeiro, conhecido pelo esforço em arrasar cidades e famílias inteiras e o segundo agindo de modo semelhante, sendo muitas vezes chamado eversor de cidades" (cf. também Odisseia I, 1-2).

${ }^{38}$ Para que se divisem alguns lampejos da "personalidade" do herói constituído por Eneias em obras gregas anteriores à Eneida e diversas da Ilíada de Homero, podem ser evocados testemunhos como os do historiador Helânico de Lesbos (ou Dionísio de Halicarnasso - séc. I a.C. -, que o cita nas Antiquitates Romanae), autor dos Troika (séc. V a.C.), bem como os do Hino homérico a Afrodite (séc. VII-VI a.C.), ocorrendo que, nesse último, entre v. 196-199, também encontremos a "profecia" de Ilíada XX, 306 et seq. sobre o fato de o herói, um dia, vir a reinar sobre os troianos, embora nascido de uma união menor de sua mãe divina com um simples mortal (BALLABRIGA, 1997, p. 34). 
Osman Lins tenha pretendido esboçar os contornos de uma personagem marcada pelos traços religiosos. Assim, embora nem sempre capaz de honrar na prática essa parte de sua caracterização heroica, por exemplo sob a forma do oferecimento de algum conforto ou, no mínimo, plena segurança física para Teresa (e sua prole), Bernardo ao menos demonstra preocupar-se constantemente com tais assuntos..$^{39}$ É a piedade, portanto, com o fato de ser Bernardo um forasteiro na nova terra que "conquista" - $\mathrm{o}$ antigo engenho abandonado -, de não haver propriamente o reforço do caráter desse herói sob o aspecto da mera força física e juventude, de ele irar-se contra os oponentes, bem como de manifestar alguma astúcia e "impulso construtor", um elemento passível de aproximá-lo de seu contraponto central na épica antiga, o próprio Eneias.

Por outro lado, sobressai como ponto central e convergente dos atos e costumes de Eneias, conforme retratado no poema de Virgílio, e de Bernardo Vieira Cedro o aspecto, sobretudo, ético da caracterização de ambos, como temos buscado apontar desde o começo deste artigo. Nesse sentido ficam atenuados, nas páginas dessa obra antiga e da moderna, excessivos contornos de figuras estritamente guerreiras de herói, como ressaltaram, para Eneias, os estudos dumezilianos que citamos (DUMÉZIL, 1986a, p. 418-419) e, bem antes, até as colocações "reabilitadoras" de Fustel de Coulanges. ${ }^{40}$ Quanto ao mesmo elemento caracterizador de Bernardo, vejam-se as palavras seguintes de Massaud Moisés, sobre o desfecho da trama de O fiel e a pedra:

Prevalece o mel da bondade humana sobre a sua animalesca ausência. E sem que se possa entrever nesse quadro um idealismo panglossiano ou utopia cega, impõe-se o poder do caráter, no qual os impulsos poéticos desempenham relevante papel. Vencem, pois, a bondade humana e um sentido poético da existência. [MOISÉS, 2007 (1974), p. 378]

\footnotetext{
${ }^{39}$ MARQUART, 2008, p. 57: "Bernardo nunca se apazigua quanto às decisões tomadas em prol do conjunto familiar. Ele se culpa, quase durante toda a história, seja por haver abandonado o emprego e, consequentemente, chegar ao ponto de não conseguir tratar a doença do filho que falece; seja por levar Teresa a viver no Surrão, sem conforto e longe dos seus: 'Você tem sofrido o que não devia sofrer - tornou Bernardo com desânimo' (OFP, 191). E sentirá um medo misturado com angústia e certa impotência pensando no futuro do filho que Teresa carrega no ventre, pensando que certas pessoas deviam permanecer solitárias: Há gente neste mundo que devia se aguentar sozinho' (OFP, 189)". ${ }^{40}$ Cf. supra nota 21.
} 
Entretanto, por último acrescentamos que uma diferença essencial entre o caráter de Bernardo e o de Eneias reside, em nossa opinião, no maior teor de rigidez da primeira personagem, a ponto de o embate entre ele e Nestor Benício ter sido descrito, por Massaud Moisés, como um confronto entre o Bem e o Mal (MOISÉS, 2007, p. 378). Também certo sonho de Teresa, em que ela experimenta um triste contato com seu filho morto, José, como se se tratasse de uma manifestação "diabólica" (LINS, 2007, p. 307-308), parece representar, talvez, a Bernardo e a mais alguém como "assassinos", contudo do "mal". ${ }^{41}$ Seria essa presença onírica um tipo de prenúncio, em O fiel e a pedra, da morte de Nestor Benício pelas mãos de Antônio Chá, espécie de "escudeiro" do herói?

Ora, assim não procedera Virgílio na pintura de um Eneias ou seu(s) oponente(s) na Eneida, fazendo o herói ou seus inimigos partilharem, em graus distintos, de boas e más qualidades, como tem ressaltado a crítica. ${ }^{42}$ Isso se dá com o próprio Eneias, capaz até da "desobediência" a seu pai, Anquises, e da manifestação da fúria mesmo contra antigos inimigos que se rendem:

Ao tratar, no livro VIII, da revolta dos etruscos contra o tirano Mezêncio, mencionara-se "fúria justa" (Ergo omnis furiis surrexit Etruria iustis, 494), bem como "ira merecida" (merita... ira, 501). Portanto, há um furor que se justifica em certos contextos. O leitor, porém, poderá sempre contrastar esse aspecto enfurecido do herói com as recomendações de Anquises a "poupar os submetidos" (parcere subiectis, 853), prescrição a que Eneias não obedece nas ações vingativas do livro X e na morte de Turno no livro XII. Além disso, ao longo do poema, a noção de furor é conotada negativamente: Juno, por exemplo, é representada constantemente como tomada de furor em seu ódio contra os troianos. Que Eneias seja

${ }^{41}$ LINS, 2007, p. 308: ““- Quem vai morrer?' '- Meu pai'. Resposta vingativa, brutal, porém com uma sombra de pranto, de rendição. Sua esperança de restaurar o entendimento perdido havia crescido e ela perguntara suavemente, como que para não o afugentar, enquanto chegava mais perto: '- Quem é teu pai?' '-É o mal'”.

${ }^{42}$ VASCONCELLOS, 2014, p. 76 (sobre eventos do canto X da Eneida): "Virgílio não retrata os personagens de forma maniqueísta, e o amor de Mezêncio a seu filho é apresentado de forma positiva". 
tomado do mesmo sentimento negativo que impele sua inimiga é, de fato, perturbador. (VASCONCELLOS, 2014, p. 75-76)

$\mathrm{Na}$ verdade, aqui não passaria despercebido aos leitores costumeiros de Virgílio que esse poeta continua a demonstrar, em sua obra derradeira, a habitual postura de projeção de luz e sombras sobre alguns dos mesmos aspectos que representa em seus versos, como Augusto (deus, v. 6) na Bucólica primeira ${ }^{43}$ e o próprio agricola dos sucessivos livros das Geórgicas. ${ }^{44}$

${ }^{43}$ Nesse poema de juventude de Virgílio - aqui, em minha tradução parcial -, o afortunado Títiro, que permanecerá em liberdade em suas terras, coloca-se em evidente contraste com o triste Melibeu, expulso do campo que um dia lhe coubera. Assim, apesar das "elogiosas" palavras do primeiro à causa inicial de suas alegrias, o próprio Otaviano Augusto (O Meliboee, deus nobis haec otia fecit:/namque erit ille mihi semper deus; illius aram/saepe tener nostris ab ouilibus imbuet agnus. - "Ó Melibeu, um deus nos deu esse sossego:/ na verdade, será ele para mim sempre um deus; ao altar dele/ amiúde embeberá um jovem cordeiro de nossos redis". - v. 5-7), é difícil não divisar no texto algum melancólico reforço das dores de quem deve partir. Vejam-se, por exemplo, as menções meio patéticas às parcas posses (em rebanhos) que Melibeu ainda logra levar consigo (Non equidem inuideo, miror magis: undique totis/ usque adeo turbatur agris! En ipse capellas/ protinus aeger ago; hanc etiam uix, Tityre, duco:/ hic inter densas corylos modo namque gemellos, / spem gregis, a! silice in nuda conixa reliquit. - "Não decerto invejo, antes admiro: em toda parte, em todos/ os campos, a tal ponto há tumulto! Eis, eu as cabras/ adiante toco infeliz; esta ainda a custo, Títiro, guio:/ pois aqui, entre densas aveleiras, há pouco dois filhos,/ esperança do rebanho, ai! deixou do parto sobre a pedra nua". - v. 11-15) e aos futuros donos - até estrangeiros! - de suas antigas terras (Impius haec tam culta noualia miles habebit?/ Barbarus has segetes? En quo discordia ciuis/ produxit miseros! His nos conseuimus agros! - "Ímpio soldado terá estas terras tão cultivadas?/ Um bárbaro estas searas? Eis aonde a discórdia os infelizes/ cidadãos conduziu! Para tais cultivamos nossos campos!" - v. 70-72). Aqui o poeta toca, na verdade, na problemática republicana de desapropriação de terras dos inimigos, por motivos políticos, e em sua futura destinação aos aliados dos vencedores nas Guerras Civis romanas (ROBERT, 1985, p. 101).

${ }^{44}$ Em Geórgicas II, 207-211, Virgílio representa a cena do corte de uma bela árvore por um cultivador "irado" (iratus, v. 207) e, sobretudo, com fortes interesses em transformar paisagens "improdutivas" em campos rendosos... Ora, tal postura de fria praticidade - a qual, inclusive, ignora a existência de ninhos com aves ainda implumes nos ramos da árvore - em nada se coaduna com os gestos de respeito mais afins ao agricola romano piedoso, diante das vezes em que precisa extrair madeira dos bosques 
[Meus agradecimentos ao Prof. Dr. Teodoro Rennó Assunção (Faculdade de Letras da UFMG), pela leitura paciente e pelas úteis sugestões, além da solícita disponibilização de bibliografia filológica].

\section{Referências}

ASSUNÇÃO, T. R. A literalidade sintática na tradução da "Eneida" por Pierre Klossowski. Aletria, Belo Horizonte, vol. XXII, n. 1, p. 69-81, jan.-abril de 2012.

BALLABRIGA, A. Survie et descendance d'Énée: le mythe grec archaïque. Kernos, Liège, vol. 9, p. 22-39, 1996.

CAIRNS, F. Virgil's Augustan epic. $1^{\text {a }}$ edição. Cambridge: Cambridge University Press, 1989.

de COULANGES, F. A cidade antiga. Trad. Fernando de Aguiar. $4^{\mathrm{a}}$ edição. São Paulo: Martins Fontes, 2004.

DUMÉZIL, G. Mythe et epopée I: l'idéologie des trois fonctions dans les épopées des peuples indo-européens. Paris: Quarto/Gallimard, 1986a [1968].

DUMÉZIL, G. Mythe et epopée II: types épiques indo-européens - un héros, un sorcier, un roi. Paris: Quarto/Gallimard, 1986b [1971].

FRITOLI, L. E. De Troia a Vitória de Santo Antão: "O fiel e a pedra" entre a ética e a estética. Revista do Centro de Estudos Portugueses, Belo Horizonte, vol. 25, n. 34, p. 131-146, jan.-dez. 2005.

GRIMAL, P. Dictionnaire de la mythologie grecque et romaine. $3^{\text {a }}$ edição. Paris: Presses Universitaires de France, 1963.

GRIMAL, P. La littérature latine. Paris: Fayard, 1994.

(TREVIZAM, 2014, p. 201-204). Não obstante, os mesmos agricolae itálicos são apresentados à maneira de uma espécie de remanescentes da Idade Áurea/ Reino de Saturno em Geórgicas II, 536-540: Ante etiam sceptrum Dictaei Regis et ante/ impia quam caesis gens est epulata iuuencis, / aureus hanc uitam in terris Saturnus agebat;/ necdum etiam audierant inflari classica, necdum/impositos duris crepitare incudibus ensis. - "Antes ainda do cetro de rei Dicteu e antes/ que o ímpio povo se banqueteasse com novilhos sacrificados,/ o áureo Saturno levava essa vida nas terras;/ além disso, ainda não ouviram inflarem-se as trombetas, ainda não/ crepitarem espadas postas sobre as duras bigornas". (trad. minha) 
HACQUARD, G.; DAUTRY, J. \& MAISANI, O. Guide romain antique. Paris: Hachette, 1952.

HOMERO. Ilíada. Trad. Carlos Alberto Nunes. Rio de Janeiro: Ediouro, 2002.

HOMERO. Odisseia. Trad., posfácio e notas de Trajano Vieira. $1^{\text {a }}$ edição. São Paulo: Editora 34, 2011.

LINS, O. O fiel e a pedra. São Paulo: Cia. das Letras, 2007.

MARQUART, R. W. A. O fiel e a pedra e as epopeias clássicas: diálogos e tessituras. 2008. 271 p. Tese (Tese de doutorado, Departamento de Teoria Literária e Literatura Comparada). São Paulo: FFLCH-USP, 2008. MOISÉS, M. Dicionário de termos literários. $15^{\mathrm{a}}$ edição. São Paulo: Cultrix, 2011 [2004].

MOISÉS, M. "O fiel e a pedra", hoje (posfácio). In: LINS, O. O fiel e a pedra. São Paulo: Cia. das Letras, 2007 [1974], p. 375-381.

OLIVANETO, J. Breve anatomia de um clássico. In: VIRGÍLIO. Eneida. Trad. Carlos Alberto Nunes, organização, apresentação e notas de João Angelo Oliva Neto. $1^{a}$ edição. São Paulo: Editora 34, 2014, p. 9-65.

ROBERT, J.-N. La vie à la campagne dans l'Antiquité romaine. $1^{\mathrm{C}}$ édition. Paris: LesBellesLettres, 1985.

ROBERT, J.-N. Rome. Paris: Les Belles Lettres, 2004.

SCHEID, J. La religion des Romains. Paris: Armand Colin, 2010.

TANNUS, C. A. K. A “Eneida”. In: APPEL, M. B.; GOETTEMS, M. B. (org.). As formas do épico. Porto Alegre: Editora Movimento, 1992, p. 72-82.

TREVIZAM, M. Mal e violência nas "Geórgicas" de Virgílio. In: de OLIVEIRA, F.; SILVA, M. F.; BARBOSA, T. V. R. (org.). Violência e transgressão: uma trajetória da humanidade. $1^{\mathrm{a}}$. edição. Coimbra/São Paulo: Universidade de Coimbra/Annablume, 2014, p. 189-229.

VASCONCELLOS, P. S. Efeitos intertextuais na "Eneida" de Virgílio. $1^{\text {a }}$ edição. São Paulo: Humanitas/Fapesp, 2001.

VASCONCELLOS, P. S. Épica I: Ênio e Virgílio. $1^{\mathrm{a}}$ edição. Campinas: Unicamp, 2014.

VIRGILE. Bucoliques. Texte établi et trad. par E. de Saint-Denis. $2^{\mathrm{e}}$. tirage. Paris: Les Belles Lettres, 2002 [1997]. 
VIRGILE. Géorgiques. Texte trad. par E. de Saint-Denis; introd., notes et postface par J. Pigeaud. Paris: Les Belles Lettres, 1998 [1982].

VIRGÍlLIO. Eneida. Trad. Carlos Alberto Nunes, organização, apresentação e notas de João Angelo Oliva Neto. $1^{\text {a }}$ edição. São Paulo: Editora 34, 2014. 
